\title{
Evaluating the "Tape Tea" Myth as Low Cost Abuse Drug through Mass Spectrometry
}

\author{
Eraldo L. Lehmann, ${ }^{a, b}$ Deleon N. Correa, ${ }^{c, d}$ Eduardo M. Schmidt, ${ }^{c}$ Marcos N. Eberlin ${ }^{c}$ \\ and Marco A. Z. Arruda $* a, b$ \\ ${ }^{a}$ Instituto Nacional de Ciência e Tecnologia (INCT) de Bioanalítica, ${ }^{b}$ Grupo de Espectrometria, \\ Preparo de Amostras e Mecanização (GEPAM) and 'Laboratório ThoMSon de Espectrometria de \\ Massas, Instituto de Química, Universidade Estadual de Campinas (Unicamp), \\ CP 6154, 13083-970 Campinas-SP, Brazil
}

${ }^{d}$ Superintendência de Polícia Técnico-Científica (SPTC), 05507-060 São Paulo-SP, Brazil

The role of the "tape tea" as a low cost abuse drug is evaluated, by searching for possible inorganic and organic compounds after its preparation. Two energy sources are evaluated (conventional and microwave heating) for preparing the "tape tea" using new or used cassette (K7) or video home system (VHS) tapes. After optimizing all the inductively coupled plasma mass spectrometry (ICP-MS) conditions, the remarkable presence of $\mathrm{Mn}$ and $\mathrm{Co}$, as well as $\mathrm{Cr}$ and $\mathrm{Ni}$, at concentrations higher than 5 times those allowed for drinking water, makes the use of the "tape tea" plausible as a non-cost abuse drug due to some possible neurotoxic effects. Regarding the Fourier transform ion cyclotron resonance mass spectrometry (FT-ICR-MS) analysis, no evidence of any organic compound related to neurological effects was found.

Keywords: ICP-MS, FT-ICR-MS, forensic chemistry, bizarre drug of abuse

\section{Introduction}

Mankind has always sought to enjoy life as much as possible, since this is part of our intrinsic nature. In modern societies, however, this concept was apparently distorted, and some forms of addiction were then closely related to make a more pleasant life. The consumption of alcoholic beverages and cigars, for instance, spread fast within society. Since life style of humanity is changing constantly, the way of enjoying life is also following the same frenetic dynamic. New forms of addiction, therefore, have supposedly become necessary, and several abuse drugs such as marijuana, lysergic acid diethylamide (LSD), ecstasy, and cocaine were introduced with the appeal of making life even more enjoyable. ${ }^{1}$ Inside this dynamic, and searching for possible low cost abuse drugs, other "routes" to more enjoyable life have appeared such as "salt baths", "incense", ", "mushrooms", ${ }^{3}$ and "spice". ${ }^{4}$ A quite exotic example has been curiously named "tape tea", which is an infusion of video home system (VHS) and cassette (K7) tapes. Prepared similarly to a tea infusion, such infusions are inexpensive since they use currently discarded old-fashioned tapes, which are easily found in home and industrial garbage cans. The "tape tea" has been said to cause hallucinations, aggressive behavior and loss of consciousness. Internet searches indicate that such effects have been associated with the presence of lead and mercury.

As mass spectrometry is considered a consolidated technique for the sort of applications in the literature regarding characterization and detection of drugs, ${ }^{5-7}$ then inorganic and organic mass spectrometry techniques can generate powerful information regarding a given system. ${ }^{8}$ Following this criteria, this work has evaluated the chemical composition of the "tape tea" for extracting important information in its prediction as a potential abuse drug. For this task, the "tape tea" was prepared using different sources of energy (conventional or microwave heating) for the extraction procedure, and metals and organic components were screened/determined by inductively coupled plasma mass spectrometry (ICP-MS) and Fourier transform ion cyclotron resonance mass spectrometry (FT-ICR-MS), respectively.

*e-mail: zezzi@iqm.unicamp.br 


\section{Experimental}

\section{Reagents and samples}

All solutions were prepared using deionized water (18.2 $\mathrm{M} \Omega \mathrm{cm}$ ) from a Milli-Q system (Millipore, USA). K7 and VHS used tapes were purchased in local secondhand stores. Elemental standards of manganese, lead, mercury, cobalt, nickel, chromium, calcium and titanium, and a multi-elemental one, were used for ICP-MS and inductively coupled plasma optical emission spectrometry (ICP OES) analyses. Liquid argon (White Martins, Brazil) was employed as carrier gas, and methane (White Martins) was employed in the reaction cell of the ICP-MS for Mn, $\mathrm{Cr}$ and $\mathrm{Ni}$ determinations.

Nitric acid (Merck, Germany), distilled in a sub boiling system (Berghof, Germany), was employed for elemental analysis, and formic acid and high performance liquid chromatography (HPLC)-grade methanol (Burdick \& Jackson, USA) were employed in FT-ICR-tandem MS (MS/MS) determinations.

\section{Instruments}

Elemental analyses were carried out using a PerkinElmer ELAN DRC-e ICP-MS (Norwalk, CT, USA). Operation parameters of ICP-MS were adjusted daily, and checked as recommended by the manufacturer, using $\mathrm{Mg}$, In, Ce and $\mathrm{U}$ solutions at $1 \mu \mathrm{g} \mathrm{\textrm {L } ^ { - 1 }}$ and $\mathrm{Ba}$ at $10 \mu \mathrm{g} \mathrm{\textrm {L } ^ { - 1 }}$, for obtaining $\mathrm{CeO}^{+} / \mathrm{Ce}^{+}$and $\mathrm{Ba}^{2+} / \mathrm{Ba}^{+}$counts ratio below $3 \%$, as well as $\mathrm{Mg}^{+}, \mathrm{In}^{+}$and $\mathrm{U}^{+}$counts higher than 5000, 25000 and 20000 cts, respectively. Table 1 summarizes the instrumental conditions used for ICP-MS. A Thermo ICap 6300 Duo Series ICP OES (England) was also used for accuracy purposes. Operational parameters of ICP OES are presented in Table 2.

A Thermo Scientific FT-ICR-MS (Germany) was used for evaluating possible organic species present in the infusions. Table 3 summarizes the main FT-ICR-MS conditions. For data treatment, software Xcalibur ${ }^{\circledR} 2.0$ (Thermo Scientific) was employed.

A hot plate (Corning, USA) or a domestic microwave oven (CCE, Brazil) were employed for preparing the infusions.

Infusion preparation

K7 and VHS tapes were separated into two groups: (i) group 1, unused $\mathrm{K} 7$ or VHS tapes, purchased on the internet; and (ii) group 2, used K7 or VHS tapes, randomly purchased in local second-hand shops, comprising different
Table 1. Operational conditions of ICP-MS

\begin{tabular}{lc}
\hline Instrumental parameter & \\
\hline Spray chamber & cyclonic \\
Nebulizer & concentric \\
RF power / W & 1200 \\
Nebulizer Ar flow / $\left(\mathrm{L} \mathrm{min}^{-1}\right)$ & $0.73-0.80$ \\
Auxiliary Ar flow / $\left(\mathrm{L} \mathrm{min}^{-1}\right)$ & $1.2-1.3$ \\
\hline Measurement & \\
\hline Scan mode & peak hopping \\
Dwell time / ms & 50 \\
Delay time / ns & 60 \\
Sweep & 5 \\
Integration time / ms & 1000 \\
Replicate & 5 \\
\hline
\end{tabular}

RF: radio frequency.

Table 2. Operational conditions of ICP OES

\begin{tabular}{lc}
\hline Parameter & Value \\
\hline Spray chamber & cyclonic \\
Nebulizer & Meinhard \\
Nebulizer gas flow / $\left(\mathrm{L} \mathrm{min}^{-1}\right)$ & 0.50 \\
Auxiliary gas flow / $\left(\mathrm{L} \mathrm{min}^{-1}\right)$ & 1.50 \\
RF power / W & 1300 \\
Plasma view & axial \\
Line / nm & $257.610(\mathrm{Mn})$ \\
\hline
\end{tabular}

RF: radio frequency.

Table 3. Operational conditions of FT-ICR-MS

\begin{tabular}{lc}
\hline Parameter & Value \\
\hline Source type & ESI \\
Capillary temperature / ${ }^{\circ} \mathrm{C}$ & 280 \\
Source voltage / kV & 3.6 \\
Source current / $\mu \mathrm{A}$ & 100 \\
Capillary voltage / V & 12 \\
Tube lens voltage / V & 85 \\
Skimmer offset / V & 0 \\
Lens 0 voltage / V & -5.5 \\
Multipole 0 offset / V & -6 \\
Lens 1 voltage / V & -38 \\
Gate lens offset / V & -34 \\
Multipole 1 offset / V & -9.5 \\
Front lens voltage / V & -6.75 \\
\hline FSI &
\end{tabular}

ESI: electrospray ionization. 
brands and years of recording. No information regarding their playing time was possible. For each group, five tapes were randomly taken for infusion preparation. The magnetic strips of a $\mathrm{K} 7$ tape (mass varying from 6 to $10 \mathrm{~g}$ of whole strips) or VHS tape (pieces of the magnetic strip, ca. $4 \mathrm{~g}$ ) were placed in a beaker. For mimicking the current conditions employed by users of such drugs, ca. $200 \mathrm{~mL}$ of water were then added, the beaker covered with a watch glass, and heated in a hot plate to boiling. All the mixture was performed with a glass rod. After 5 min boiling, the heating was stopped and the resulting infusion cooled at room temperature. When using microwave oven for heating, the mixtures were heated for $5 \mathrm{~min}$, stopping the heating each $30 \mathrm{~s}$ for mixing the infusion with a glass rod, and preventing strong boiling which may cause infusion spill inside the oven. After 5 min of boiling, the heating was stopped and the infusion cooled at room temperature. After cooling, the colorless infusions were filtered, and volume completed to $250 \mathrm{~mL}$ with deionized water in a volumetric flask. These infusions were diluted at least 5 times with $1 \%$ (v/v) nitric acid and analyzed by ICP-MS.

For FT-ICR-MS/MS analyses, infusions were diluted $1: 1(\mathrm{v} / \mathrm{v})$ using $0.1 \%(\mathrm{v} / \mathrm{v})$ formic acid (positive mode) or ammonia (negative mode), both in methanol, and their electrospray ionization (ESI)(+)-MS or ESI(-)-MS mass spectra were obtained with high resolution(100000@450).

\section{Results and Discussion}

\section{Semi-quantitative analyses by ICP-MS}

Metals were analyzed by ICP-MS, using the "total-quant" tool of the equipment. In such analysis, just one standard was employed, and concentrations of the elements in the samples were estimated by comparing their counts with those for the standard. These results may be, however, overestimated or underestimated, but they give a good idea regarding the presence or absence of the analytes in the samples.

The results showed a high content of manganese in the K7 infusion, as well as substantial amounts of cobalt, chromium and nickel. Although lead and mercury were not detected, these elements were also evaluated in the quantitative mode because they characterize the myth surrounding the toxicity effects of such infusions.

\section{Quantitative analysis by ICP-MS}

\section{Optimization of reaction cell}

For minimizing isobaric interferences, such as ${ }^{40} \mathrm{Ar}^{12} \mathrm{C}^{+}$ for ${ }^{52} \mathrm{Cr}^{+},{ }^{40} \mathrm{Ar}^{13} \mathrm{C}^{+}$for ${ }^{53} \mathrm{Cr}^{+},{ }^{40} \mathrm{Ar}^{14} \mathrm{~N}^{1} \mathrm{H}^{+}$for ${ }^{55} \mathrm{Mn}^{+},{ }^{44} \mathrm{Ca}^{16} \mathrm{O}^{+}$ and ${ }^{43} \mathrm{Ca}^{16} \mathrm{O}^{1} \mathrm{H}^{+}$for ${ }^{60} \mathrm{Ni}^{+},{ }^{44} \mathrm{Ca}^{16} \mathrm{O}^{1} \mathrm{H}^{+}$for ${ }^{61} \mathrm{Ni}^{+}$, and ${ }^{46} \mathrm{Ca}^{16} \mathrm{O}^{+}$ and ${ }^{46} \mathrm{Ti}^{16} \mathrm{O}^{+}$for ${ }^{62} \mathrm{Ni}^{+}$, a dynamic collision reaction (DCR) cell filled with methane was employed, which is recommended by the manufacturer. Lead, mercury and cobalt have no significant isobaric interferences.

A solution containing $50 \mu \mathrm{g} \mathrm{L}^{-1}$ of $\mathrm{Mn}, \mathrm{Cr}$, Ni (analytes), and $\mathrm{Ca}$ and $\mathrm{Ti}$ (Ni-interfering), was employed for the preliminary optimization. Methane flow-rate (FR) and potential of the cell rods $(\mathrm{RP} q)$ were optimized, in a univariated way. Although the ICP-MS has low resolution, isotope ratio was evaluated. Figures 1 and 2 summarize the ICP-MS results. The results for ${ }^{55} \mathrm{Mn}^{+}$are observed in Figures 1a and 2a only, because it is a monoisotopic species.
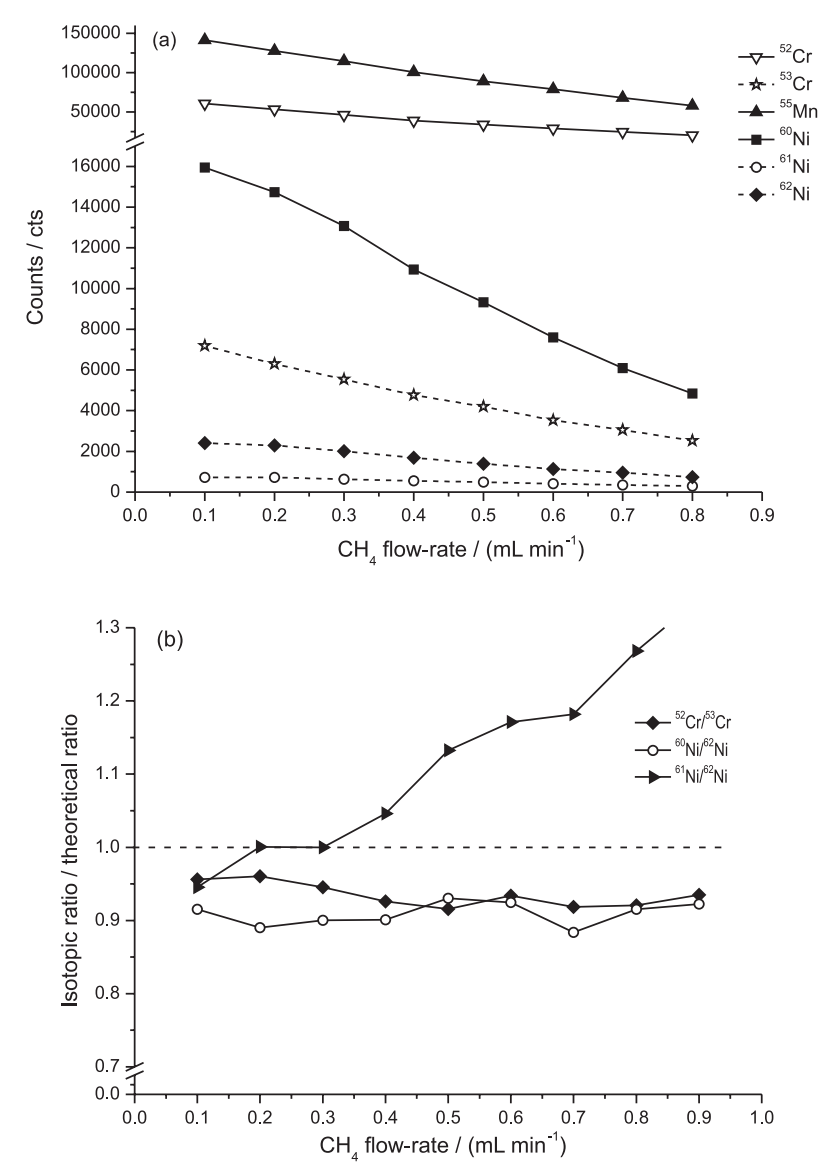

Figure 1. (a) Counts for each element as a function of $\mathrm{CH}_{4}$ flow-rate and (b) isotopic ratio / theoretical ratio for (a). $\mathrm{RP} q$ at $0.7 \mathrm{~V}$.

From Figures $1 \mathrm{~b}$ and $2 \mathrm{~b}$, it is noted that ${ }^{52} \mathrm{Cr}^{+} / 53 \mathrm{Cr}^{+}$and ${ }^{60} \mathrm{Ni}^{+} /{ }^{62} \mathrm{Ni}^{+}$ratios are more constant than ${ }^{61} \mathrm{Ni}^{+} / 62 \mathrm{Ni}^{+}$. Since there are a wide acceptable range for the methane flow-rate and a narrower range for $\mathrm{RP} q$, the choice of the best condition is difficult. For this purpose, therefore, a factorial design $\left(2^{2}\right)$ at central point was applied for optimization. The flow-rate values were $0.4\left(\mathrm{FR}_{-}\right)$and $0.8\left(\mathrm{FR}_{+}\right) \mathrm{mL} \mathrm{min}^{-1}$ for $\mathrm{RP} q 0.6\left(\mathrm{RP} q_{-}\right)$and $0.8\left(\mathrm{RP} q_{+}\right) \mathrm{V}$, respectively. Central point was then determined considering the average values $-0.6 \mathrm{~mL} \mathrm{~min}^{-1}\left(\mathrm{FR}_{0}\right)$ and $0.7 \mathrm{~V}\left(\mathrm{RP} q_{0}\right)$. 

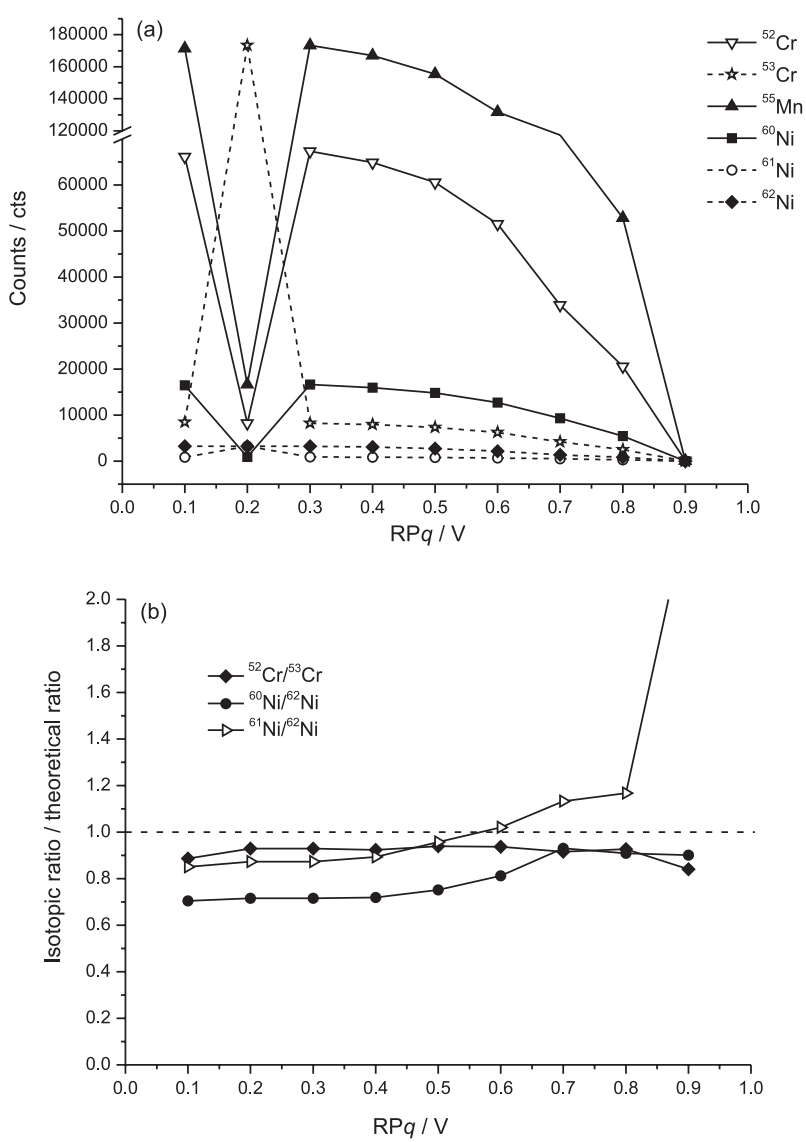

Figure 2. (a) Counts for each element as a function of $\mathrm{RP} q$ and (b) isotopic ratio / theoretical ratio for (a). $\mathrm{CH}_{4}$ flow-rate at $0.5 \mathrm{~mL} \mathrm{~min}^{-1}$.

As the interference for $\mathrm{Cr}$ and $\mathrm{Mn}$ is mostly $\mathrm{Ar}$, Ni was evaluated in the second optimization only. Four solutions (1\% (v/v) $\mathrm{HNO}_{3}, 100 \mu \mathrm{g} \mathrm{L}{ }^{-1} \mathrm{Ca}+100 \mu \mathrm{g} \mathrm{L} \mathrm{T}^{-1} \mathrm{Ti}, 50 \mu \mathrm{g} \mathrm{L}^{-1}$ $\mathrm{Ni}$, and $50 \mu \mathrm{g} \mathrm{L}{ }^{-1} \mathrm{Ni}+100 \mu \mathrm{g} \mathrm{L}^{-1} \mathrm{Ca}+100 \mu \mathrm{g} \mathrm{L}^{-1} \mathrm{Ti}$ ) were employed in this step. Solutions of $1 \%(\mathrm{v} / \mathrm{v}) \mathrm{HNO}_{3}$ and $100 \mu \mathrm{g} \mathrm{L} \mathrm{L}^{-1} \mathrm{Ca}+100 \mu \mathrm{g} \mathrm{\textrm {L } ^ { - 1 }} \mathrm{Ti}$ were used for evaluating the increase of the blank signal by the interferents, and solutions of $50 \mu \mathrm{g} \mathrm{L}-1 \mathrm{Ni}$, and $50 \mu \mathrm{g} \mathrm{L} \mathrm{L}^{-1} \mathrm{Ni}+100 \mu \mathrm{g} \mathrm{L}^{-1}$ $\mathrm{Ca}+100 \mu \mathrm{g} \mathrm{L}^{-1} \mathrm{Ti}$, for evaluating the increase of analyte signal (Figure 3).

Comparing Figures $3 \mathrm{a}$ and $3 \mathrm{~b}$, the central point (0.7 V RP $q ; 0.6 \mathrm{~mL} \mathrm{~min}^{-1} \mathrm{CH}_{4}$ flow-rate) shows the lowest values for the blank. Student's $t$-test for the average, and F-test for the variance, corroborate that they can be the same at $95 \%$ of confidence. This condition was not attained for other points.

Figures $3 \mathrm{c}$ and $3 \mathrm{~d}$ show the highest counts at FR_ and $\mathrm{RP} q_{\text {. }}$. Student's $t$-test and F-test corroborate that they could be considered the same at $95 \%$ of confidence level. The blank solution showed, however, the highest count at this condition, which means that interferents cause a high blank signal, promoting an increase on the limit of quantification (LOQ). Central point showed the second highest counts for ${ }^{60} \mathrm{Ni}^{+}$, and they could be considered the same at $95 \%$ of confidence level in the presence and absence of $\mathrm{Ca}$ and Ti. For this reason, the central point was defined as $0.7 \mathrm{~V}$ for $\mathrm{RP} q$ and $0.6 \mathrm{~mL} \mathrm{~min}{ }^{-1}$ for $\mathrm{CH}_{4}$ flow-rate, and it was chosen as the best condition for determining $\mathrm{Ni}$ in presence of $\mathrm{Ti}$ and $\mathrm{Ca}$.

The accuracy was checked using the National Institute of Standards and Technology (NIST) standard reference material (SRM) 1643e ("Trace Elements in Water"), which contains $\mathrm{Ca}, \mathrm{Cr}, \mathrm{Mn}, \mathrm{Co}, \mathrm{Ni}$ and $\mathrm{Pb}$ as certified values. Table 4 shows the results obtained (in $\mu \mathrm{g} \mathrm{L}^{-1}$ ) for all determined elements. Mercury has no certified value. For lead, mercury and cobalt, the use of DCR cell was not necessary. The ${ }^{61} \mathrm{Ni}^{+}$ and ${ }^{62} \mathrm{Ni}^{+}$isotopes did not show acceptable recoveries, and as they have lower natural abundance than ${ }^{60} \mathrm{Ni}^{+}$, these isotopes were then not evaluated. For ${ }^{60} \mathrm{Ni}^{+}$, a correction equation (equation 1) is recommended by the manufacturer when $\mathrm{Ca}$ concentration is higher than Ni. Considering this certified material, the $\mathrm{Ca}$ concentration $\left(32300 \pm 1100 \mu \mathrm{g} \mathrm{L}^{-1}\right)$ is 500 times higher than the one for $\mathrm{Ni}$.

$\mathrm{C}_{60_{\mathrm{Ni}}}=\frac{100}{26.233 \times\left(\mathrm{C}_{m / z=60}-0.0025 \times \mathrm{C}_{m / z=13}\right)}$

\section{Elemental determination in $\mathrm{K} 7$ and VHS tapes infusion}

The efficiency of the extraction using conventional and microwave heating was compared. Microwave heating achieved extraction far below normal heating for all tested analytes, including lower than the LOQ for cobalt. This phenomenon can be explained by the water density, which changes during heating, causing the floating of the magnetic stripe, affecting the contact between the phases. This phenomenon was observed during heating. As a consequence, reduction of the extraction efficiency was noted. Another hypothesis is the absorption of the microwave radiation by the magnetic stripes instead of the water, reducing the extraction efficiency. For this reason, only the conventional heating was used in later experiments.

Infusions were analyzed, and the metals determined according to the conditions described in Table 1, employing a DCR cell for $\mathrm{Ni}, \mathrm{Cr}$ and $\mathrm{Mn}$, as previously optimized. Tapes were divided into groups of new (1) and used (2) K7 and VHS tapes, and five replicates of infusions from each group were performed and evaluated (indicated as 1-5) in Table 5. As Mn showed a high concentration for those infusions made from $\mathrm{K} 7$ tape, this element was also determined using ICP OES equipment. For this task, two new infusions were made with unused tapes and determined using both ICP-MS and ICP OES. Results are present in Table 6 , which are in agreement with both techniques, at 95\% confidence level. 
(a)

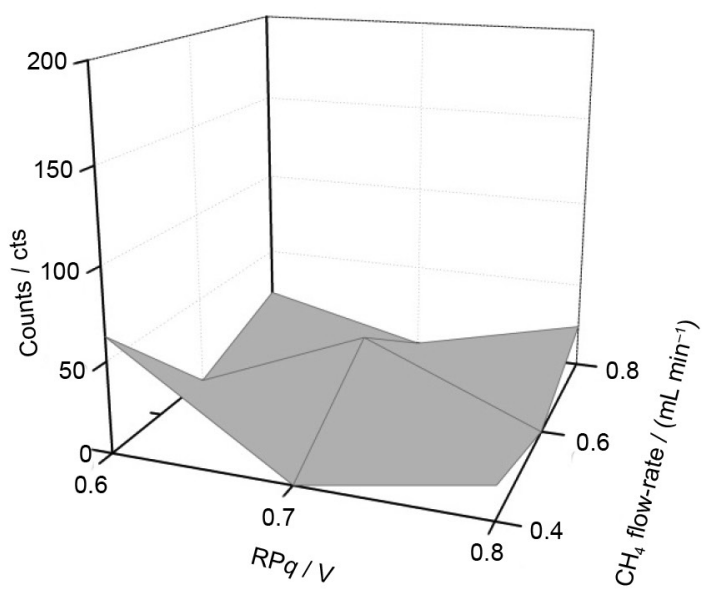

(c)

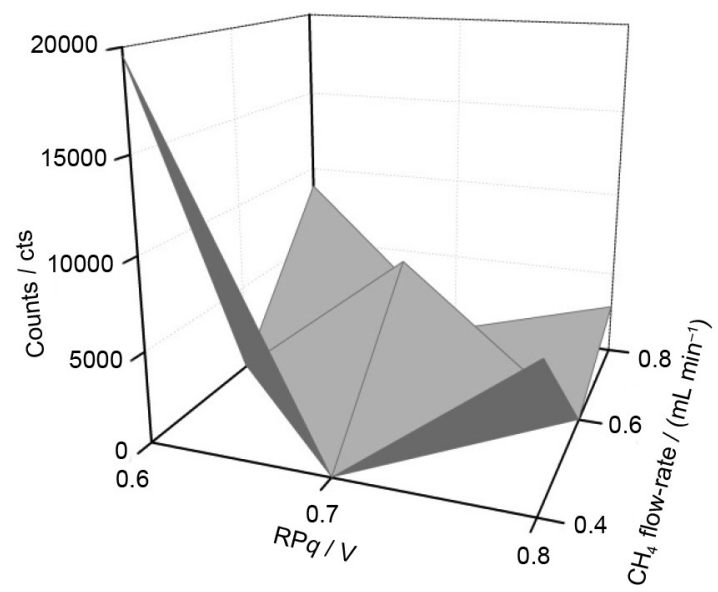

(b)

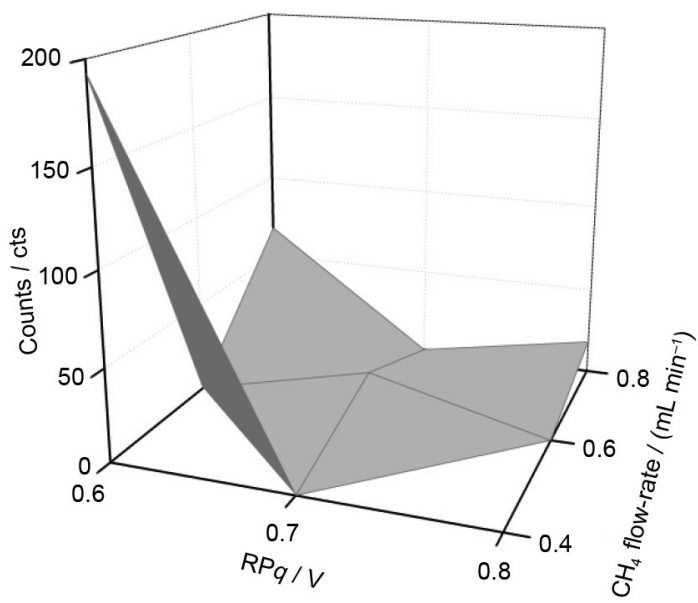

(d)

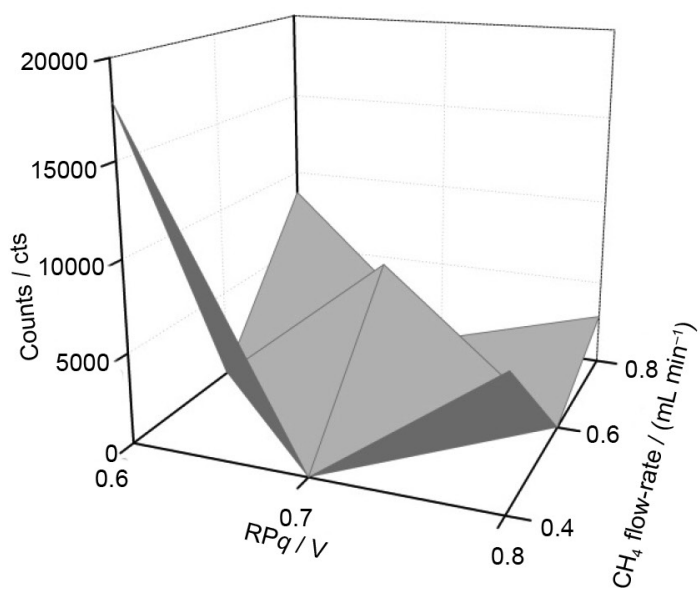

Figure 3. Response surface obtained at $m / z=60$ for (a) $1 \%$ (v/v) $\mathrm{HNO}_{3}$; (b) $100 \mu \mathrm{g} \mathrm{L}{ }^{-1} \mathrm{Ca}+100 \mu \mathrm{g} \mathrm{L}-1 \mathrm{Ti}$; (c) $50 \mu \mathrm{g} \mathrm{L} \mathrm{L}^{-1} \mathrm{Ni}$; (d) $50 \mu \mathrm{g} \mathrm{L} \mathrm{Li}^{-1} \mathrm{Ni} 100 \mu \mathrm{g} \mathrm{L} \mathrm{Ca}^{-1}$ $100 \mu \mathrm{g} \mathrm{L} \mathrm{Li}^{-1}$.

Table 4. Accuracy check after optimizing ICP-MS conditions. Concentration results in $\mu \mathrm{g} \mathrm{L^{-1 }}$

\begin{tabular}{|c|c|c|c|}
\hline Isotope & $\begin{array}{c}\text { Certified value / } \\
\qquad\left(\mu \mathrm{g} \mathrm{L}^{-1}\right)\end{array}$ & $\begin{array}{l}\text { Concentration } \\
\text { found }^{\mathrm{a}} /\left(\mu \mathrm{g} \mathrm{L}^{-1}\right)\end{array}$ & Recovery / \% \\
\hline${ }^{52} \mathrm{Cr}^{+}$ & $20.40 \pm 0.24$ & $24 \pm 2$ & 115.8 \\
\hline${ }^{55} \mathrm{Mn}^{+}$ & $38.97 \pm 0.45$ & $36 \pm 2$ & 91.48 \\
\hline${ }^{59} \mathrm{Co}^{+}$ & $27.06 \pm 0.32$ & $26 \pm 3$ & 97.93 \\
\hline${ }^{60} \mathrm{Ni}^{+}$ & $62.41 \pm 0.69$ & $69 \pm 4$ & 111.0 \\
\hline${ }^{202} \mathrm{Hg}^{+}$ & - & $<\mathrm{LOQ}^{\mathrm{b}}$ & - \\
\hline${ }^{208} \mathrm{~Pb}^{+}$ & $19.63 \pm 0.21$ & $19 \pm 2$ & 97.69 \\
\hline
\end{tabular}

${ }^{\mathrm{a}}$ Uncertainty represented by the standard deviation; ${ }^{b}$ limit of quantification (LOQ): $59 \mathrm{ng} \mathrm{L}^{-1}$.

Lead and mercury concentrations were lower than the LOQ, which were far below the maximum values allowed for drinking water (10 and $6 \mu \mathrm{g} \mathrm{L} \mathrm{L}^{-1}$ for $\mathrm{Pb}$ and $\mathrm{Hg}$, respectively).
For K7 tapes infusion, Mn was present at higher concentrations than those limits for drinking water.,10 Manganese can cause manganism, ${ }^{11}$ which is a neurodegenerative disease, similar to Parkinson's disease, causing bradykinesia (slow movements) and widespread rigidity (common in both diseases), besides more frequent dystonia, more propensity to fall backwards and a characteristic walking posture, called "cock-walk", where patients with manganism walk on their toes with the elbows flexed and spine erected. In addition, Mn exposure can cause hematological, endocrinal and male reproductive effects. ${ }^{11} \mathrm{Al}$-Zubaidy and Mohammad ${ }^{12}$ have observed an increase in the tonic immobility and latency in the movements of chicks after intramuscular injection of manganese solution, demonstrating that one of the acute effects of manganese poisoning could be a lethargic state. The high concentration of Mn found in the K7 tape 
Table 5. Determination of some elements in the infusions

\begin{tabular}{|c|c|c|c|c|}
\hline \multirow{2}{*}{ Infusion } & \multicolumn{4}{|c|}{ Concentration $^{\mathrm{a}} /\left(\mu \mathrm{g} \mathrm{L}^{-1}\right)$} \\
\hline & $\mathrm{Mn}$ & $\mathrm{Cr}$ & $\mathrm{Ni}$ & Co \\
\hline K7 1.1 & $2085 \pm 42$ & $2.4 \pm 0.4$ & $<$ LOQ & $3.11 \pm 0.08$ \\
\hline K7 1.2 & $1927 \pm 31$ & $2.6 \pm 0.3$ & $<$ LOQ & $3.24 \pm 0.04$ \\
\hline K7 1.3 & $2105 \pm 38$ & $2.2 \pm 0.1$ & $<$ LOQ & $3.1 \pm 0.1$ \\
\hline K7 1.4 & $2010 \pm 42$ & $<\mathrm{LOQ}$ & $<\mathrm{LOQ}$ & $3.0 \pm 0.1$ \\
\hline K7 1.5 & $2151 \pm 73$ & $5.4 \pm 0.6$ & $<$ LOQ & $3.18 \pm 0.01$ \\
\hline VHS 1.1 & $6.2 \pm 0.6$ & $<\mathrm{LOQ}$ & $<\mathrm{LOQ}$ & $3.47 \pm 0.04$ \\
\hline VHS 1.2 & $8.9 \pm 0.8$ & $<$ LOQ & $<$ LOQ & $9.6 \pm 0.3$ \\
\hline VHS 1.3 & $9 \pm 1$ & $<$ LOQ & $<$ LOQ & $8.8 \pm 0.4$ \\
\hline VHS 1.4 & $10 \pm 1$ & $2.3 \pm 0.3$ & $<$ LOQ & $12.6 \pm 0.1$ \\
\hline VHS 1.5 & $9.2 \pm 0.5$ & $2.2 \pm 0.2$ & $<$ LOQ & $11.6 \pm 0.3$ \\
\hline K7 2.1 & $1722 \pm 22$ & $<$ LOQ & $172 \pm 3$ & $6.1 \pm 0.1$ \\
\hline K7 2.2 & $1054 \pm 23$ & $<$ LOQ & $9 \pm 1$ & $2.8 \pm 0.1$ \\
\hline K7 2.3 & $908 \pm 7$ & $<\mathrm{LOQ}$ & $303 \pm 12$ & $3.99 \pm 0.03$ \\
\hline K7 2.4 & $711 \pm 9$ & $<$ LOQ & $14 \pm 1$ & $22.8 \pm 0.3$ \\
\hline K7 2.5 & $2007 \pm 18$ & $<$ LOQ & $182 \pm 3$ & $17.4 \pm 0.3$ \\
\hline VHS 2.1 & $<$ LOQ & $752 \pm 34$ & $<$ LOQ & $11.2 \pm 0.3$ \\
\hline VHS 2.2 & $<$ LOQ & $691 \pm 13$ & $<\mathrm{LOQ}$ & $13.1 \pm 0.2$ \\
\hline VHS 2.3 & $<\mathrm{LOQ}$ & $695 \pm 19$ & $<\mathrm{LOQ}$ & $12.5 \pm 0.1$ \\
\hline VHS 2.4 & $<$ LOQ & $547 \pm 19$ & $<$ LOQ & $11.2 \pm 0.1$ \\
\hline VHS 2.5 & $<$ LOQ & $668 \pm 13$ & $<\mathrm{LOQ}$ & $12.0 \pm 0.4$ \\
\hline LOQ & 1.35 & 0.60 & 2.2 & 0.055 \\
\hline $\mathrm{MPV}^{\mathrm{b}}$ & $100^{\mathrm{c}} / 400^{\mathrm{d}}$ & 50 & 70 & - \\
\hline
\end{tabular}

${ }^{\mathrm{a}}$ Uncertainty represented by the standard deviation; ${ }^{\mathrm{M}} \mathrm{MPV}$ : maximum permitted value for drinking water, according to World Health Organization (WHO $)^{9}$ and Brazilian Ministry of Health $;{ }^{10}$ corganoleptic value, according to $\mathrm{WHO}^{9}$ and Brazilian Ministry of Health; ${ }^{10}$ doxicological value, according to $\mathrm{WHO}^{9}$ and Brazilian Ministry of Health. ${ }^{10}$ Infusions marked as 1.(1-5) are unused and those marked as 2.(1-5) are used; K7: cassette tape; VHS: video home system tape; LOQ: limit of quantification.

Table 6. Results for Mn (in $\mu \mathrm{g} \mathrm{L}^{-1}$ ) from ICP-MS and ICP OES determinations

\begin{tabular}{lcc}
\hline \multirow{2}{*}{ Infusion } & \multicolumn{2}{c}{ Mn concentration $/\left(\mu \mathrm{g} \mathrm{L}^{-1}\right)$} \\
\cline { 2 - 3 } & $\mathrm{ICP}-\mathrm{MS}$ & $\mathrm{ICP}$ OES \\
\hline K7 3.1 & $1888 \pm 11$ & $1890 \pm 15$ \\
K7 3.2 & $1697 \pm 40$ & $1683 \pm 11$ \\
\hline
\end{tabular}

ICP-MS: inductively coupled plasma mass spectrometry; ICP OES: inductively coupled plasma optical emission spectrometry; K7: cassette tape.

infusions may explain the lethargic state reported by some "tape tea" users.

Chromium was also found at concentrations higher than those allowed for drinking water in five used VHS tape infusions. While $\mathrm{Cr}^{\mathrm{VI}}$ is known as mutagenic, genotoxic and carcinogenic, $\mathrm{Cr}^{\text {III }}$ can cause anomalies in chromosomes and interfere in DNA replication process. ${ }^{13}$
Nickel was found at concentrations higher than that allowed for drinking water for three used K7 tape infusions. This variation could be explained by manufacture, age and level of use of the tapes. Nickel is a carcinogenic (nickel and their salts belong to group 1 carcinogen agents) and genotoxic element, but it can also cross the placenta and the blood-testis barriers, which are important for fertility and proper development of embryos. ${ }^{14}$ It can also accumulate in lung, kidney, liver and testicles. At molecular level, nickel can cause oxidative stress and replaces zinc in proteins, for instance protamine $2(\mathrm{P} 2)$, which is responsible for production and maturation of sperm cells in mammals, which could cause male infertility. ${ }^{14}$

Cobalt concentration has no reported limit for drinking water, but the increase of this element in blood higher than $1.905 \mathrm{nmol} \mathrm{L}^{-1}$ (ca. $0.112 \mu \mathrm{g} \mathrm{L}^{-1}$ ) is known to cause atrophy in the optical nerve and damages on macula (central region of retina).$^{15} \mathrm{As} \mathrm{Co}^{2+}$ is a $\mathrm{Ca}^{2+}$ blocker, it could also suppress communication between photoreceptors and second-order neurons, which is a $\mathrm{Ca}^{2+}$-dependent process. ${ }^{16}$ Gallemore and Steinberg ${ }^{16}$ applied Co to young chick retinas, and using an electric circuit, they observed that $3 \mathrm{mmol} \mathrm{L}^{-1}$ (ca. $50 \mu \mathrm{g} \mathrm{L}^{-1}$ ) can affect dark base-line measurement, light-evoked peak and amplitude of light-wave detected when compared with control experiments. Cobalt may explain those vision problems reported by some "tape tea" users. In addition, acute effects of cobalt intoxication were evaluated in rats, which include sedation, diarrhea, decrease of body temperature, respiratory disturbance, tremor and convulsions. ${ }^{17}$

\section{Organic compounds evaluation in K7 and VHS tapes infusion}

After ionizing the organic compounds in a negative or positive mode, some ions potentially associated with infusion constituents were fragmented for characterizing the chemicals. Although accurate masses are assessed through the FT-ICR-MS equipment for obtaining exact molecular formulas for most components, as well as MS/MS data for revealing fragmentation patterns, no structural assignments could be made. Additionally, common drugs such as cocaine, ecstasy, tetrahydrocannabinol (THC) and LSD, which could be related to effects reported in the internet by the "tape tea" users, were not identified in such infusions.

\section{Conclusions}

The myth of K7 or VHS "tape tea" as an abuse drug was found to be plausible mainly due to the relative high concentrations of $\mathrm{Mn}$ and $\mathrm{Co}$ in the infusions. $\mathrm{Mn}$ is neurotoxic, causing a lethargic state, whereas Co can cause 
damage in the macula and optical nerve. The presence of other less abundant elements in the "tape tea" infusions could also boost the toxicological effects. Additionally, sometimes due to the conditions of the users, the placebo effect should not be discarded. Although it seems to be highly advertised, both lead and mercury were not found at concentrations above those commonly found in drinking water. Therefore, they are not likely candidates for the effects of "tape tea". In terms of organic analysis by FT-ICR-MS, no structural assignments were achieved, indicating the absence of those possible drugs related to the effects reported by the "tape tea" users, or that possible thermal degradation could be occurring in such compounds, producing no conclusive identification.

\section{Acknowledgments}

The authors thank FAPESP, CAPES, and CNPq for financial support.

\section{References}

1. Dickerson, E. M.; Jones, P.; Wilkins, D.; Regnier, J.; Prahlow, J.; Am. J. Forensic Med. Pathol. 2013, 34, 29.

2. Jerry, J.; Collins, G.; Streem, D.; Cleve. Clin. J. Med. 2012, 79, 258.

3. Appendino, G.; Taglialatela-Scafati, O.; Nat. Prod. Rep. 2014, 31,865 .

4. Spaderna, M.; Addy, P. H.; D’Souza, D. C.; Psychopharmacology 2013, 228, 525.

5. Saar, E.; Beyer, J.; Drug Test. Anal. 2012, 4, 376.
6. Demoranville, L. T.; Verkouteren, J. R.; Talanta 2013, 106, 375.

7. Bassan, D. M.; Erdmann, F.; Krüll, R.; Anal. Bioanal. Chem. 2011, 400, 43.

8. Santos Jr., J. C.; Mollo Filho, P. C.; Guidugli, R. B. F.; Eberlin, M. N.; Pessôa, G. S.; Silva, E. G.; Arruda, M. A. Z.; Höehr, N. F.; Metallomics 2014, 6, 1801.

9. World Health Organization (WHO); Guidelines for DrinkingWater Quality, 4 ${ }^{\text {th }}$ ed.; Gutenberg: Malta, 2011.

10. Ministério da Saúde do Brasil (Brazilian Ministry of Health); Portaria No. 2914; December 12, 2011, http://bvsms.saude.gov. br/bvs/saudelegis/gm/2011/prt2914_12_12_2011.html accessed in February 2016.

11. Santamaria, A. B.; Indian J. Med. Res. 2008, 128, 484.

12. Al-Zubaidy, M. H. I.; Mohammad, F. K.; Arh. Hig. Rada Toksikol. 2013, 64, 69.

13. Mamyrbaev, A. A.; Dzharkenov, T. A.; Imangazina, Z. A.; Satybaldieva, U. A.; Environ. Health Prev. Med. 2015, 20, 159.

14. Murawska-Ciałowicz, E.; Bal, W.; Januszewskz, L.; Zawadzki, M.; Zuwała-Jagiełło, J.; Sci. World J. 2012, 2012, 1.

15. Lim, C. A.; Khan, J.; Chelva, E.; Khan, R.; Unsworth-Smith, T.; Doc. Ophthalmol. 2015, 130, 43.

16. Gallemore, R. P.; Steinberg, R. H.; Invest. Ophthalmol. Visual Sci. 1991, 32, 3041.

17. Speijers, G. J.; Krajnc, E. I.; Berkvens, J. M.; van Logten, M. J.; Food Chem. Toxicol. 1982, 20, 311.

Submitted: January 6, 2016

Published online: February 24, 2016

FAPESP has sponsored the publication of this article. 